\title{
Struktur Pasar dalam Pandangan Islam
}

\author{
Haris Al Amin ${ }^{1}$, Marliyah $^{2}$, Syawal Harianto ${ }^{3 *}$, Asmaul Husna ${ }^{4}$, Abi Waqqash ${ }^{5}$ \\ 1,3 Politeknik Negeri Lhokseumawe, Kota Lhokseumawe Provinsi Aceh, Indonesia. \\ 2,4 Universitas Islam Negeri Sumatera Utara, Medan, Provinsi Sumatera Utara, \\ Indonesia. \\ ${ }^{5}$ STAI Syekh H Abdul Halim Hasan Al Ishlahiyah, Kota Binjai, Provinsi Sumatera \\ Utara, Indonesia.
}

\begin{abstract}
Abstrak. Struktur pasar dalam Islam didasarkan pada prinsip kebebasan, termasuk dalam melakukan kegiatan ekonomi tetapi masih dibatasi oleh aturan tanpa mengabaikan prinsip tanggung jawab dan keadilan. Adil dalam hal ini tidak merugikan konsumen atau produsen, terkait dengan surplus produsen dan surplus konsumen. Dalam Islam, umat Islam dianjurkan untuk berusaba apa saja selama masib dalam koridor syariah, artinya selama usaba tersebut tidak melanggar ketentuan yang ditetapkan oleb Allah SWT. Demikian pula dalam hal menjalankan kegiatan ekonomi, semuanya boleh asalkan tidak melanggar aturan tersebut. Salah satu kegiatan ekonomi dapat dilibat di pasar, tempat bertemunya penjual dan pembeli untuk melakukan transaksi barang atau jasa, baik dalam bentuk produksi maupun penetapan harga.
\end{abstract}

Kata kunci: Struktur Pasar; Pasar Sempurna; Pasar Tidak Sempurna; Ekonomi Syariah.

\begin{abstract}
Market structure in Islam is based on the principle of freedom, including in carrying out economic activities but is still limited by rules without neglecting the principles of responsibility and justice. Fair in this case is not detrimental to consumers or producers, related to producer surplus and consumer surplus. In Islam, Muslims are encouraged to try anything as long as they are still within the corridor of sharia, meaning that as long as the effort does not violate the provisions stipulated by Allah SWT. Likewise, in terms of carrying out economic activities, everything is permissible as long as it does not violate these rules. One of the economic activities can be seen in the market, where sellers and buyers meet to make transactions for goods or services, both in the form of production and pricing.
\end{abstract}

Keywords: Market Structure; Perfect Market; Imperfect Market; Islamic Economic.

*Author. Email: haris@pnl.ac.id ${ }^{1}$.marliyah@uinsu.ac.id 2*, syawalharianto@pnl.ac.id 33, asmaul25husna@gmail.com 4, abipaytren@gmail.com 5. 


\section{Pendahuluan}

Ekonomi Islam memiliki cara pandang tersendiri dalam melihat struktur pasar dalam perekonomian, Islam sebagai agama yang universal, mengatur seluruh aspek kehidupan manusia, baik yang bersifat ibadah maupun muamalah. Begitu pula ekonomi, dalam Islam diatur bagaimana perilaku konsumen dan produsen dalam menjalankan aktivitas ekonomi mereka. Interaksi- interaksi mereka dalam pasar diatur agar tidak terjadi market power yang menguntungkan satu pihak.

Struktur pasar merupakan alat untuk menganalisis sektor industri dan merupakan bagian dari kerangka pemikiran structureconduct-performance (Sri, 2008: 102). Ada beberapa bentuk pasar sebagaimana yang sudah sering diungkapkan oleh para pakar pemasaran. Adapun bentuk-bentuk pasar tersebut antara lain pasar persaingan sempurna, pasar monopoli, pasar oligopoly dan pasar persaingan monopolistik. Pengelompokkan ini didasarkan atas tinggi rendahnya derajat kompetisi atau kemampuan untuk mempengaruhi harga (market power) masingmasing (Ida, 2003: 118).

\section{Literature Review}

\section{Pasar Persaingan Sempurna dalam Islam}

Dalam ajaran Islam, pasar ditempatkan pada posisi yang proporsional berbeda dengan pandangan kapitalisme maupun sosialisme yang ekstrim. Pasar bukan satu-satunya mekanisme distribusi yang utama dalam perekonomian tetapi hanya merupakan salah satu dari berbagai mekanisme yang diajarkan syariat Islam (Anas sidik, 1991:131).

Mekanisme pasar yang Islami menurut Ibnu Taimiyah haruslah memiliki kriteria-kriteria berikut: (Anas sidik, 1991:133).

1) Orang-orang harus bebas untuk masuk dan keluar pasar. Memaksa penduduk menjual barang tanpa ada kewajiban untuk menjualnya adalah tindakan yang tidak adil dan ketidakadilan itu dilarang.

2) Tingkat informasi yang cukup mengenai kekuatan-kekuatan pasar dan barangbarang dagangan adalah perlu.

3) Unsur-unsur monopolistik harus dilenyapkan dari pasar sehingga segala bentuk kolusi antara kelompok para penjual dan pembeli tidak diperbolehkan.

4) Homogenitas dan standardisasi produk sangat dianjurkan ketika terjadi pemalsuan produk, penipuan dan kecurangankecurangan dalam mempresentasikan barang-barang tersebut.

5) Setiap penyimpangan dari kebebasan ekonomi yang jujur, seperti sumpah palsu, penimbangan yang tidak tepat, dikecam oleh ajaran Islam.

Dari pendapat Ibnu Taimiyah di atas tentang mekanisme pasar dalam Islam, kita dapat melihat mekanisme-mekanisme tersebut mengarah pada karakteristik pasar persaingan sempurna. Hal itu berarti bahwa pasar dalam Islam itulah yang dalam teori konvensional disebut dengan pasar persaingan sempurna, dimana asumsi-asumsi yang disebutkan oleh pakar ekonomi konvensional ada (ditemukan) dalam pasar yang Islami.

Salah satu contoh pasar persaingan sempurna dalam pasar Islam adalah yang terjadi pada masa khalifah Umar bin Khattab RA. Pada saat itu Umar berjalan dipasar kurma, ketika itu Umar mendapati salah seorang pedagang yang menjual dibawah harga yang ada di pasar tersebut. Umar memberikan dua pilihan pada penjual tersebut, yang pertama naikkan harga sampai sama dengan harga yang ada di pasaran atau keluar dari pasar ini.

Kisah di atas dapat ditarik kesimpulan bahwa dalam sebuah pasar persaingan sempurna harga yang ditawarkan adalah sama dengan harga yang ditawarkan oleh seluruh pedagang dalam pasar tersebut jika barang dagangan tidak terdeferensiasi (berbeda).

\section{Pasar Monopoli Dalam Pandangan Islam}

Persoalan monopoli sesungguhnya merupakan persoalan yang sangat menarik untuk dibahas. Bahkan permasalahan ini telah mendapat perhatian yang sangat serius dari ajaran Islam, potongan ayat Al Quran Al-Hasyr: 7 ditegaskan yang artinya: "Apa saja harta rampasan (fai-i) yang diberikan Allah kepada RasulNya (dari harta benda) yang berasal dari penduduk kotakota maka adalah untuk Allah, untuk rasul, kaum kerabat, anak-anak yatim, orang-orang 
miskin dan orang-orang yang dalam perjalanan, supaya harta itu jangan beredar di antara orang-orang Kaya saja di antara kamu. apa yang diberikan Rasul kepadamu, Maka terimalah. dan apa yang dilarangnya bagimu, Maka tinggalkanlah. dan bertakwalah kepada Allah. Sesungguhnya Allah Amat keras hukumannya." (QS Al-Hasyr: 7) (Al-Hikmah, Al-Qur'an dan Terjemah, 2015: 545).

Selain riba, monopoli adalah komponen utama yang akan membuat kekayaan terkonsentrasi di tangan segelintir kelompok, sehingga menciptakan kesenjangan sosial dan ekonomi. Kepemilikan dan penguasaan aset kekayaan di tangan individu adalah sesuatu yang diperbolehkan dalam Islam. Namun demikian, ketika kebebasan tersebut dimanfaatkan untuk menciptakan praktik - praktik monopolistik yang merugikan, maka adalah tugas dan kewajiban negara untuk melakukan intervensi dan koreksi. Negara bertanggung jawab penuh untuk menciptakan keadilan ekonomi, dengan memberikan kesempatan kepada setiap individu untuk berpartisipasi dalam kegiatan tersebut.

Karena itulah, beliau menekankan pentingnya keberadaan lembaga al-Hisbah sebagai organ negara yang bertugas untuk memonitor pasar, mengawasi kondisi perekonomian dan sekaligus mengambil tindakan jika terjadi ketidakseimbangan pasar akibat monopoli dan praktik-praktik lain yang tidak sesuai dengan syariat Islam. Pendapat senada juga diungkapkan oleh Ibn al-Qayyim al-Jauziyyah dalam kitabnya At-Turuk al-Hukmiyyah (Didin Hafidhuddin, 2008).

Sementara itu, Ibn Khaldun dalam kitab Muqaddimah juga menyatakan pentingnya peran negara dalam menciptakan keadilan ekonomi dan keseimbangan pasar. Ia menegaskan bahwa pajak (dan juga denda) adalah instrumen yang dapat digunakan oleh negara untuk meningkatkan pertumbuhan ekonomi, sekaligus untuk mengeliminasi praktik-praktik kecurangan yang terjadi di pasar, termasuk praktik-praktik monopoli yang dilakukan oleh segelintir pebisnis. Namun demikian, ajaran Islam membolehkan praktik monopoli yang dilakukan oleh negara, dengan syarat hanya terbatas pada bidang-bidang strategis yang menguasai hajat hidup orang banyak. Dalam sebuah hadis, Rasulullah SAW bersabda:"Manusia berserikat dalam tiga hal yaitu air, api, dan padang rumput". (HR. Abu Daud). Diperlukan langkah-langkah strategis untuk mengelola investasi yang diharapkan dapat mengembangkan perekonomian. (Muhammad, 2004:24).

Pada dasarnya dalam ekonomi Islam, monopoli tidak dilarang, siapapun boleh berusaha atau berbisnis tanpa peduli apakah dia satu-satunya penjual (monopoli) atau ada penjual lain, asalkan tidak melanggar nilai-nilai Islam. Dalam hal ini, yang dilarang berkaitan dengan monopoli adalah ikhtikar, yaitu kegiatan menjual lebih sedikit barang dari yang seharusnya sehingga harga menjadi naik untuk mendapatkan keuntungan di atas keuntungan normal, di dalam istilah ekonomi kegiatan ini disebut sebagai Monopoly's Rent Seeking Behaviour. Sehingga sekarang dapat dibedakan antara monopoli dan ikhtikar dalam terminology ekonomi Islam. Maka, di sinilah konsep monopoli yang dalam islam diartikan sebagai ikhtikar itu dilarang.

\section{Pasar Oligopoli Dalam Pandangan Ekonomi Islam}

Ketika pelaku ologopoli tidak melakukan kolusi secara aktual akan berhadapan atau menemui kurva permintaan yang berorientasi islami. Secara umum, pola struktur oligopoli yang tidak diperkenankan dalam ekonomi Islam kemungkinan munculnya moral harard di dalamnya. Islam adalah cara hidup yang imbang dan koheren, dirancang untuk kebahagiaan manusia dengan cara menciptakan keharmonisan antara kebutuhan moral, material manusia dan aktualisasi keadilan sosio-ekonomi serta persaudaraan antar umat manusia (Muhammad, 2004:32).

Berbagai aspek kehidupan dalam kehidupan sehari-hari tercermin dalam syariah dan muamalah, sehingga mengikutinya merupakan perjalanan yang harus ditempuh untuk menjadi Muslim sejati. Islam merupakan satu-satunya agama yang mengemukakan prinsip-prinsip yang meliputi semua segi kehidupan manusia, tidak hanya membicarakan tentang nilai-nilai 
ekonomi. Islam juga telah menanamkan kerangka kerja yang luas berdasarkan kesempatan berekonomi yang sama dan adil bagi penganutnya untuk mengarahkan mereka ke arah kehidupan ekonomi yang seimbang.

Sebagai agama yang komprehensif tentunya aktivitas ekonomi sebagai kegiatan vital kemanusiaan tidak luput dari perhatian. "Allah telah menghalalkan jual beli dan mengharamkan riba" (QS Al-Baqarah: 275). Pembahasan mengenai struktur pasar menjadi penting dalam ekonomi Islam, karena dalam konsep ekonomi Islam, penentuan harga didasarkan atas kekuatan-kekuatan pasar yaitu kekuatan permintaan dan kekuatan penawaran. Sebagaimana Rasulullah SAW sangat menghargai harga yang dibentuk oleh pasar sebagai harga yang adil, sehingga beliau menolak adanya suatu intervensi pasar apabila perubahan harga yang terjadi karena mekanisme harga yang wajar.

Dengan demikian, Islam menjamin pasar bebas di mana produsen dan konsumen bersaing satu sama lain dengan arus informasi yang berjalan lancar dalam kerangka keadilan, yakni tidak ada (baik individu maupun kelompok produsen, konsumen, dan pemerintah) yang zalim atau dizalimi. Kondisi ini merupakan suatu kondisi ideal yang pada tataran praktis tidak selalu seperti itu kondisinya. Sehingga distorsi pasar (market distortion) yang menyebabkan pasar tidak bekerja pada kondisi yang ideal menjadi pembahasan paling vital dalam ekonomi Islam.

\section{Pasar Monopolistik dalam Pandangan Islam}

Dalam perspektif Islam pasar persaingan monopolistik tidak memandang bahwasanya struktur pasar tersebut sebagai suatu hal yang salah (M. Nur Rianto dan Euis Amalia, 2016: 260). Disatu sisi kondisi tersebut memang tidak optimal jika dibandingkan dengan struktur pasar persaingan sempurna, namun apabila situasi dan kondisi pada akhirnya mengarahkan terwujudnya struktur pasar tersebut maka dalam Islam tidak menjadi sebuah masalah. Yang dilarang dalam Islam adalah ketika pelaku pasar tersebut melakukan kolusi dengan maksimalisasi laba pada tingkat harga yang lebih tinggi, output dan pekerja lebih rendah.
Untuk menjaga keseimbangan pasar dalam sejarahnya islam memiliki lembaga khusus yang mengawasi pasar pada dasarnya Al-hisbah merupakan pelaksanaan dari al-amr bi al-ma'ruf wa nahi'an al munkar, dan mendamaikan di antara manusia yang berselisih. Lembaga ini juga bertugas mengawasi takaran dan timbangan, mengawasi pasar dari kecurangan dan tipuan. Dengan demikian lembaga ini bertugas memberikan pertolongan kepada orang yang tidak mampu menuntut haknya dan menyelesaikan perselisihan yang terjadi diantara manusia serta mengajak kepada kebaikkan.

\section{Metodologi Penelitian}

Penelitian ini menggunakan metode penelitian kualitatif berdasarkan studi kepustakaan (library research) (Moelong, 2006). Penelitian ini dilakukan dengan mengumpulkan artikel buku dan jurnal dengan tema sesuai dengan tujuan penelitian yaitu Strukturpasar dalam pandangan Islam Sumber data primer diperoleh dari seluruh karya yang ditulis langsung oleh tokoh pemikir ekonomi Islam, Sementara sumber data sekunder, diambil dari karya-karya ilmiah yang terkait dengan topik pembahasan, ditambah dengan tulisan-tulisan dalam disiplin ilmu ekonomi Islam yang dibantu oleh software Publish or Perish untuk menghimpun artikel jurnal yang relevan dan selanjutnya melakukan analisis isi (content analysis). Analisis konten merupakan suatu teknik penelitian untuk menghasilkan deskripsi yang objektif dan sistematik mengenai isi yang terkandung dalam media yang diteliti (Zuchdi, 1993).

Teknik ini dilakukan melalui tiga tahapan yaitu pertama tahap reduksi data yakni data yang diperoleh dari artikel jurnal dilakukan reduksi, dirangkum dan dipilih hal-hal yang pokok dan difokuskan pada hal-hal yang penting serta disusun secara sistematis sesuai dengan tujuan penelitian agar data tersebut menjadi lebih mudah dipahami dan dikendalikan. Kedua display data yaitu menampilkan merupakan informasi yang diperoleh sebagai hasil dari reduksi data yang memungkinkan adanya penarikan kesimpulan dan pengambilan data sesuai dengan tujuan penelitian. Ketiga Penarikan Kesimpulan atau Verifikasi di mana peneliti mencari makna dari data yang 
dikumpulkan dan melakukan penarikan kesimpulan yang lebih mendasar sesuai dengan tujuan penelitian (Moleong, 2006).

\section{Hasil dan Pembahasan}

Islam merupakan sistem kehidupan yang bersifat komprehensif, yang mengatur semua aspek, baik dalam sosial, ekonomi, dan politik maupun kehidupan yang bersifat spiritual (Mustafa Edwin Nasution, dkk, 2012:1). Sebagaimana firman-Nya QS. An-nahl ayat 89 yang artinya: (dan ingatlah) akan hari (ketika) Kami bangkitkan pada tiap-tiap umat seorang saksi atas mereka dari mereka sendiri dan Kami datangkan kamu (Muhammad) menjadi saksi atas seluruh umat manusia. dan Kami turunkan kepadamu Al kitab (Al Quran) untuk menjelaskan segala sesuatu dan petunjuk serta rahmat dan kabar gembira bagi orang-orang yang berserah diri. (QS. An-nahl ayat 89) (AlHikmah, Al-Qur'an dan terjemah, 2015:268).
Transaksi jual beli dibolehkan dalam Islam selama tidak mengandung riba dan hal-hal yang dapat merugikan salah satu pihak, sebagaimana Allah SWT berfiman dalam QS. Al-Baqarah ayat 275, yang artinya: Orang-orang yang Makan (mengambil) riba tidak dapat berdiri melainkan seperti berdirinya orang yang kemasukan syaitan lantaran (tekanan) penyakit gila. Keadaan mereka yang demikian itu, adalah disebabkan mereka berkata (berpendapat), Sesungguhnya jual beli itu sama dengan riba, Padahal Allah telah menghalalkan jual beli dan mengharamkan riba. orang-orang yang telah sampai kepadanya larangan dari Tuhannya, lalu terus berhenti (dari mengambil riba), Maka baginya apa yang telah diambilnya dahulu (sebelum datang larangan); dan urusannya (terserah) kepada Allah. orang yang kembali (mengambil riba), Maka orang itu adalah penghuni-penghuni neraka; mereka kekal di dalamnya. (QS. Al-Baqarah ayat 275) (AlHikmah, Al-Qur'an dan terjemah, 2015:48).

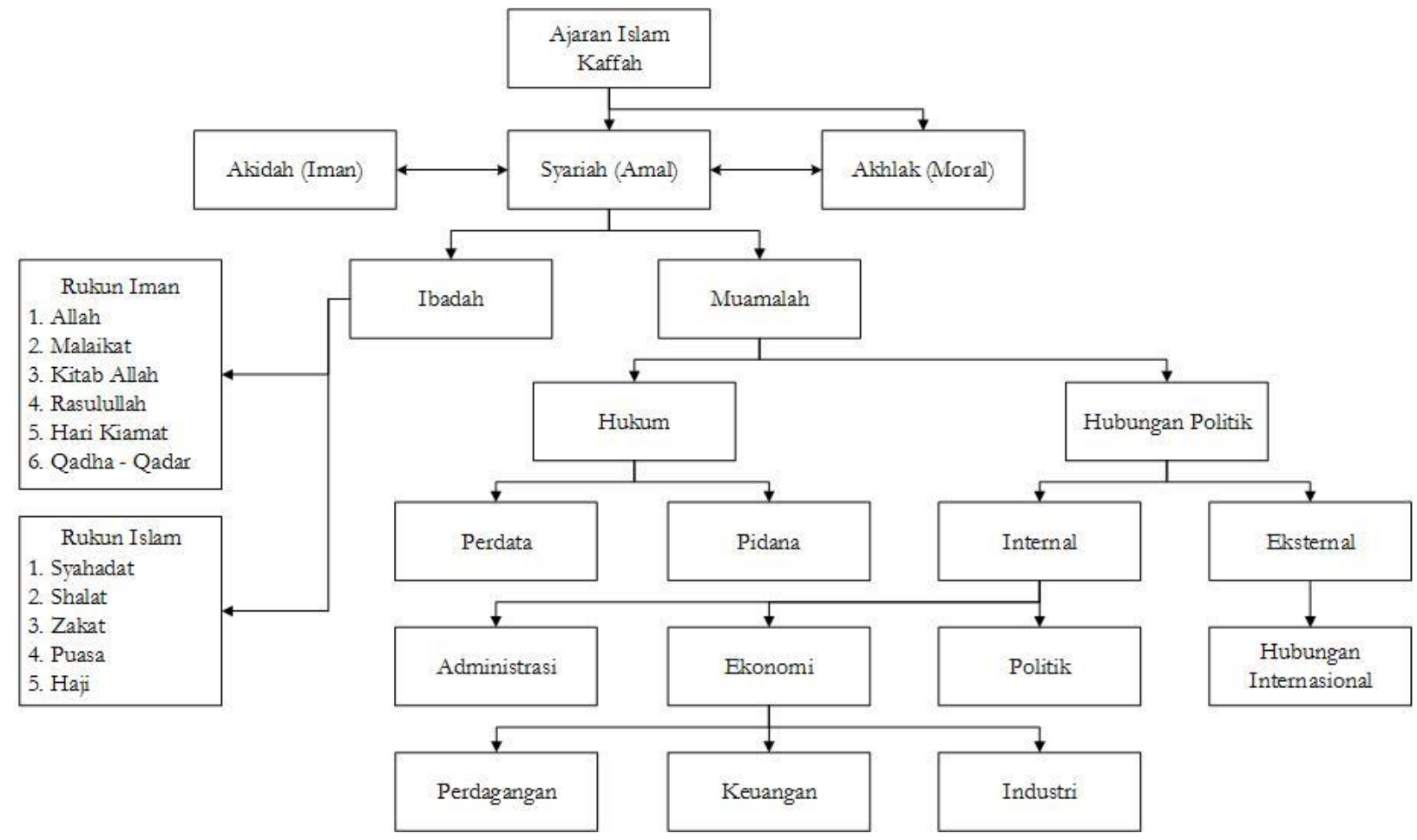

Gambar 2. Skema Pondasi Ekonomi Islam. (Ika Yunia Fauzia \& Abdul Kadir Riyadi, 2015: 12)

Ekonomi Islam adalah ekonomi yang berdasarkan ke-Tuhanan. Sistem ini bertitik tolak dari Allah, bertujuan akhir kepada Allah, dan menggunakan sarana yang tidak lepas dari syariat Allah. Pada skema dibawah ini dapat kita lihat bagaimana pondasi ekonomi dalam Islam.
Mekanisme pasar yang dibangun dalam Islam berdasarkan norma ajaran Islam yang berhubungan dengan aktivitas ekonomi. Mekanisme pasar bukanlah suatu hal yang sempurna atau baku sehingga dimungkinkan gagal dalam mencapai tujuan ekonomi. Disinilah dibutuhkan intervensi agar mekanisme 
pasar berjalan sesuai dengan kepentingan perekonomian yang Islami.

\section{Kesimpulan}

Dari keempat bentuk pasar diatas yang paling ideal adalah pasar persaingan sempurna karena dianggap dapat mendorong roda perekonomian secara efisien, karena terjadi persaingan yang seimbang sehingga membentuk persaingan yang sehat.

Konsep Islam menegaskan bahwa pasar harus berdiri di atas prinsip persaingan bebas (perfect competition), namun demikian bukan berarti kebebasan tersebut berlaku mutlak, akan tetapi kebebasan dengan frame aturan syariah. Dan konsep yang menentukan bahwa pasar islami harus bisa menjamin adanya kebebasan masuk atau keluarnya sebuah komoditas di pasar berikut perangkat faktorfaktor produksinya. Hal ini dimaksudkan untuk menjamin adanya pendistribusian kekuatan ekonomi dalam sebuah mekanisme yang proporsional. Agar pasar dapat berperan secara normal (alamiah) dan terjamin keberlangsungannya, dimana struktur dan mekanisme pasar dapat terhindar dari perilakuperilaku negatif para pelaku pasar, maka ajaran islam juga menawarkan aturan moral berbasis syariah yang melindungi setiap kepentingan pelaku pasar.

\section{Daftar Pustaka}

A. Karim, Adiwarman. (2007) Ekonomi Mikro Islami, PT. RajaGrafindo Persada Jakarta.

Adiningsih, Sri dan Kadarusman. (2008) Teori Ekonomi Mikro edisi ke-2, BPFE Yogyakarta, Yogyakarta.

Alam, (2008) Ekonomi. Erlangga, Jakarta.

Al-Hikmah, (2015). Al-Qur'an dan Terjemah, Diponegora: Bandung.

Edwin Nasution, Mustafa dkk. (2012) Pengenalan Eksklusif Ekonomi Islam, Kencana Prenada Media Group Jakarta.
Fauzia, Ika Yunia \& Abdul Kadir Riyadi, (2015). Prinsip Dasar Ekonomi Islam: perspektif maqashid al-syariah, Prenadamedia Group, Jakarta.

Hafidhuddin, Didin, monopoli dalam pandangan islam, http://www.republika.co.id, edisi minggu 15 juni 2008

Juliati Nasution, Yenni Samri, (2018). AtTawassuth, Vol. III, No. 1, Mekanisme Pasar Dalam Perspektif Ekonomi Islam, Fakultas Ekonomi Dan Bisnis Islam UINSU Medan.

Manurung, Mandala dan Prathama Raharja, (2008). Pengantar Ilmu ekonomi, Penerbit FEUI, Jakarta.

Moleong, j, Lexy. (2006). Metodologi Penelitian Kualitatif. Bandung: PT. Remaja Rosdakarya.

Muhammad, (2004). Ekonomi Mikro dalam Perspektif Islam, BPFE, Yogyakarta.

Nuraini, Ida, (2003). Pengantar Ekonomi Mikro, UMM Press, Malang.

Putong, Iskandar, (2003). Pengantar Ekonomi Mikro dan Makro, Ghalia Indonesia, Jakarta.

Rianto M. Nur dan Euis Amalia, (2016). Teori Mikroekonomi: suatu perbandingan ekonomi islam dan ekonomi konvensional, Prenada Media, Jakarta.

Rozalinda (2017). Ekonomi Islam: Teori dan Aplikasinya pada Aktifitas Ekonomi, Raja Grafindo Persada, Depok.

Samuelson, Paul A, Williiam D. Nordhaus, Terj.A.Q. Khalid. (1986). Ekonomi, Erlangga, Jakarta.

Sidik, Anas, (1991) Kegiatan Ekonomi dalam Islam, Bumi Aksara, Jakarta. 
Sukirno, Sadono (2013) Mikro Ekonomi: Teori Pengantar edisi ke3, PT. Grafindo Persada, Jakarta.

Varian, R, (2003), Intermediate Microeconomic: Library of Congres Cataloging, New York.
Zuchdi, Darmiyati. (1993). Panduan Penelitian Analisis Konten. Yogyakarta: Lembaga Penelitian IKIP Yogyakarta. 